\title{
ACTUALIZACIÓN Y UTILIDAD DE LOS PRINCIPIOS DE DERECHO EUROPEO DEL CONTRATO DE SEGURO (PEDCS)*
}

\author{
UPDATING AND USEFULNESS OF PRINCIPLES \\ OF EUROPEAN INSURANCE CONTRACT LAW (PEICL)
}

\author{
ALBERTO J. TAPIA HERMIDA** \\ Fecha de recepción: 28 de octubre de 2020 \\ Fecha de aceptación: 30 de enero de 2021 \\ Disponible en línea: 30 de diciembre de 2021
}

Para citar este artículo/To cite this article

TAPIA Hermida, Alberto J. Actualización y utilidad de los principios de derecho europeo del contrato de seguro (PEDCS), 55 Rev.Ibero-Latinoam.Seguros, 15-40 (2021). https://doi. org/10.11144/Javeriana.ris55.aupd doi:10.11144/Javeriana.ris55.aupd

\footnotetext{
* Artículo de reflexión.

** Licenciado en Derecho por la Universidad Autónoma de Madrid. Doctor en Derecho por la Universidad Complutense de Madrid. Es Abogado de ESTUDIO JURÍDICO SÁNCHEZ CALERO. Ha sido Letrado de la Comisión Nacional del Mercado de Valores. Es experto en Derecho de seguros y ha intervenido en numerosos litigios relativos a este sector. También tiene una dilatada experiencia en mercados financieros y en Derecho bancario y bursátil. Emite dictámenes e informes en asuntos mercantiles y ha sido requerido para actuar como experto en procedimientos judiciales y arbitrales. Catedrático de Derecho mercantil. Facultad de Derecho. Universidad Complutense de Madrid. Vicepresidente de SEAIDA. Contacto: atapia@, sanchezcalero.com; Orcid: https://orcid.org/0000-0002-5736-1611
} 


\section{RESUMEN}

Este estudio tiene por objeto analizar de que manera los Principios de Derecho Europeo del Contrato de Seguro (PEDCS) puede servir de espacio de colaboración de los juristas del seguro iberoamericanos. Para ello, comienza realizando unas reflexiones iniciales sobre los PDECS que abarcan su utilidad actual, su origen y los motivos para reactivar esta iniciativa en el momento presente. En segundo lugar, examina la noción del contrato de seguro y de sus elementos fundamentales en los PDECS y su contenido que ordena en tres apartados que exponen las disposiciones generales sobre el contrato de seguro y las disposiciones especiales sobre los seguros de daños (en particular, el seguro de responsabilidad civil) y los seguros de personas (en particular, el seguro sobre la vida).

Palabras clave: Principios de Derecho Europeo del Contrato de Seguro (PEDCS), seguros de daños, seguro de responsabilidad civil, seguros de personas, seguro sobre la vida

\section{ABSTRACT}

The purpose of this study is to analyze how the Principles of European Insurance Contract Law (PEICL) can serve as a space for collaboration for Ibero-American insurance lawyers. To do this, it begins by making some initial reflections on the PEICL that include their current usefulness, their origin and the reasons for reactivating this initiative at the present time. Secondly, it examines the notion of the insurance contract and its fundamental elements in the PEICL and its content that it orders in three sections that expose the general provisions on the insurance contract and the special provisions on damage insurance (in particular, liability insurance) and personal insurance (in particular life insurance).

Keywords: Principles of European Insurance Contract Law (PEICL), damage insurance, liability insurance, personal insurance, life insurance 


\section{SUMARIO}

I. PRESENTACIÓN: LOS PRINCIPIOS DE DERECHO EUROPEO DEL CONTRATO DE SEGURO (PEDCS) COMO ESPACIO DE COLABORACIÓN DE LOS JURISTAS DEL SEGURO IBEROAMERICANOS. I. PRESENTACIÓN: LOS PRINCIPIOS DE DERECHO EUROPEO DEL CONTRATO DE SEGURO (PEDCS) COMO ESPACIO DE COLABORACIÓN DE LOS JURISTAS DEL SEGURO IBEROAMERICANOS. II. REFLEXIONES INICIALES SOBRE LOS PRINCIPIOS DE DERECHO EUROPEO DEL CONTRATO DE SEGURO (PDECS).A) Utilidad actual de los Principios de Derecho Europeo del Contrato de Seguro (PDECS). 1. Origen de los Principios de Derecho europeo del contrato de seguro (PDECS). 2. Motivos para reactivar la iniciativa de los Principios de Derecho europeo del contrato de seguro (PDECS) en el momento presente. a) Una razón estructural: La asimetría paradójica radical de la regulación aseguradora en la UE. b) Una razón coyuntural: El incremento del papel que el contrato de seguro está llamado a tener a raíz de la pandemia universal del COVID 19.3. La necesaria armonización de los contratos de seguro en el seno de la UE. B) La noción del contrato de seguro y de sus elementos fundamentales en los PDECS. 1. El contrato de Seguro. 2. El riesgo asegurado. 3. La prima. III. CONTENIDO DE LOS PRINCIPIOS DE DERECHO EUROPEO DEL CONTRATO DE SEGURO (PDECS). A) Disposiciones generales sobre el contrato de seguro. 1. Documentación. 2. Conclusión. 3. Duración. 4. Modificación de cláusulas y condiciones. 5. Finalización tras el acaecimiento del siniestro. 6. Deberes del tomador. 7. Deberes del asegurador. 8. Contratos de seguro de grupo. B) Seguros de daños. 1. Noción. 2. Las disposiciones generales aplicables a todos los seguros indemnizatorios. 3. Las disposiciones especiales sobre el seguro de responsabilidad civil. C) Seguros de personas. 1. Noción. 2. Disposiciones generales de los seguros de sumas o de personas. 3. Disposiciones especiales del seguro sobre la vida. II. REFLEXIONES INICIALES SOBRE LOS PRINCIPIOS DE DERECHO EUROPEO DEL CONTRATO DE SEGURO (PDECS). A) Utilidad actual de los Principios de Derecho Europeo del Contrato de Seguro (PDECS). 1. Origen de los Principios de Derecho europeo del contrato de seguro (PDECS). 2. Motivos para reactivar la iniciativa de los Principios de Derecho europeo del contrato de seguro (PDECS) en el momento presente. a) Una razón estructural: La asimetría paradójica radical de la regulación aseguradora en la UE. b) Una razón coyuntural: El incremento del papel que el contrato de seguro esta llamado a tener a raíz de la pandemia universal del COVID 19. 3. La necesaria armonización de los contratos de seguro en el seno de la UE. B) La noción del contrato de seguro y de sus elementos fundamentales en los PDECS. 1. El contrato de Seguro. 2. El riesgo asegurado. 3. La prima. III. CONTENIDO DE LOS PRINCIPIOS DE DERECHO EUROPEO DEL CONTRATO DE SEGURO (PDECS). A) Disposiciones generales sobre el contrato de seguro. 1. Documentación. 2. Conclusión. 3. Duración. 4. Modificación de cláusulas y condiciones. 5. Finalización tras el acaecimiento del siniestro. 6. Deberes del tomador. 7. Deberes del asegurador. 8. Contratos de seguro de grupo. B) Seguros de daños. 1. Noción. 2. Las disposiciones generales aplicables a todos los seguros indemnizatorios. 3. Las disposiciones especiales sobre el seguro de responsabilidad civil. C) Seguros de personas. 1. Noción 2. Disposiciones generales de los seguros de sumas o de personas. 3. Disposiciones especiales del seguro sobre la vida. 


\section{PRESENTACIÓN: LOS PRINCIPIOS DE DERECHO EUROPEO DEL CONTRATO DE SEGURO (PEDCS) COMO ESPACIO DE COLABORACIÓN DE LOS JURISTAS DEL SEGURO IBEROAMERICANOS}

Desde el comienzo mismo de la pandemia del COVID 19 que lleva azotando la vida del Orbe entero y especialmente la existencia de los países iberoamericanos a partir del inicio de este año 2020 hemos insistido en la utilidad del seguro como instrumento extremadamente útil para afrontar los nuevos retos que plantea para las vidas y las haciendas de las personas ofreciendo cobertura a un costo parcial gracias a la mutualización de dicha cobertura recíproca frente a estos nuevos y viejos riesgos. Uno de los ejemplos más importantes que nos depara la práctica internacional reciente del empleo virtuoso del contrato de seguro para atender una cobertura esencial es la iniciativa de 109 aseguradoras españolas a través de UNESPA de suscribir tres Pólizas simétricas de seguro de vida en régimen de coaseguro, conforme al artículo 33 de la LCS española -en las que actúan como entidades abridoras GENERALI ESPAÑA S.A. DE SEGUROS Y REASEGUROS, MAPFRE VIDA, S.A. de Seguros y Reaseguros sobre la Vida Humana y VIDACAIXA S.A.U. DE SEGUROS Y REASEGUROScreado para proteger a los profesionales sanitarios y de las residencias de mayores que luchan más directamente contra el COVID-19 en España. Para ello, las aseguradoras han constituido un fondo solidario dotado de 38 millones de euros que sirve para el pago de las primas del seguro de tres pólizas que incorporan una arquitectura jurídica original que implica soluciones por completo innovadoras ${ }^{1}$.

Si desde una perspectiva general, pasamos a la específica del contrato de seguro, debemos afirmar que, siendo este contrato la "unidad atómica" de la actividad aseguradora; todo avance en la armonización internacional de las normas y principios que lo rigen será beneficioso para luchar contra la pandemia que nos azota. Y esta oportunidad de la armonización de las normas y principios del contrato de seguro que es cierta en general, lo es más aún cuando nos referimos a países que comparten una cultura jurídica común como somos los países iberoamericanos.

Es por ello por lo que, desde la Sección Española de la Asociación Internacional de Derecho de Seguros (SEAIDA) queremos ofrecer a los países hermanos de CILA un vértice de confluencia y un espacio de colaboración en la armonización de las normas y principios del contrato de seguro partiendo de los Principios de Derecho Europeo del Contrato de Seguro (PEDCS). Y en esta iniciativa se inscribe este estudio ${ }^{2}$.

\footnotetext{
1 El lector puede encontrar referencia detallada a las características de estas pólizas en nuestro estudio sobre "Las medidas extraordinarias adoptadas en España y Europa en los seguros y en los planes de pensiones para combatir las consecuencias de la pandemia del COVID 19”, que publicamos en este misma Revista Ibero-Latinoamericana de Seguros. Vol. 29, n. ${ }^{o} 52$ (2020), pp.15-36.

$2 \mathrm{Su}$ origen se ubica en la ponencia sobre los "Princípios do Direito Europeu do Contrato de Seguro (PEICL)" que tuve la oportunidad de impartir el pasado día 15 de octubre de 2020 en el Aula virtual del III Curso de Pós-Graduação em Direito dos Seguros organizado por el prestigioso Centro de Investigação de Direito Privado de la Universidad de Lisboa. Ofrecí una síntesis de su contenido en cuatro entradas que publiqué en mi blog financiero (ajtapia.com) los días 16, 19, 22 y 23 de octubre de 2020.
} 


\section{REFLEXIONES INICIALES SOBRE LOS PRINCIPIOS DE DERECHO EUROPEO DEL CONTRATO DE SEGURO (PDECS)}

\section{A) Utilidad actual de los Principios de Derecho Europeo del Contrato de Seguro (PDECS)}

\section{Origen de los Principios de Derecho europeo del contrato de seguro (PDECS)}

Los Principios de Derecho Europeo del Contrato de Seguro (PDECS) (Principles of European Insurance Contract Law, PEICL) son fruto de la labor desarrollada por el grupo de investigación "Restatement of European Insurance Contract Law" (http:// www.restatement.info/) compuesto por 21 profesores provenientes de diferentes países de la Unión Europea y Suiza y fundado en 1999 por el Prof. Reichert-Facilides sobre la base de los argumentos expuestos en el Congreso de Basilea de 1998 acerca de la conveniencia de reactivar el proceso de unificación de la regulación sobre contrato de seguro en la Unión Europea ${ }^{3}$. El grupo adoptó como método de trabajo el modelo de los "Restatments" americanos; metodología que ya había sido probada con éxito en Europa por la denominada Comisión Lando que había alumbrado sus Principios de Derecho Contractual Europeo. Procede aclarar que, en la esfera jurídica, "Restatement" es un término técnico que proviene de los Estados Unidos de América, para describir un cuerpo que condensa reglas jurídicas provenientes de diferentes pero similares fuentes, sistematizadas y unificadas en el sentido de una "mejor solución". Posteriormente, la Comisión Europea, a través de las Comunicaciones de 2003 y $2004^{4}$ acogió la idea de desarrollar un Marco común de Referencia para el Derecho contractual europeo, incorporándose el grupo "Restatement of European Insurance Contract Law" a la red de excelencia que surgió con tal finalidad (www.copecl.org).

\section{Motivos para reactivar la iniciativa de los Principios de Derecho europeo del contrato de seguro (PDECS) en el momento presente}

Consideramos que, en el momento presente, existen dos tipos de motivos que aconsejan reactivar la iniciativa de los Principios de Derecho europeo del contrato

\footnotetext{
3 El lector interesado puede consultar el texto de los PEDCS en J. Basedow, J. Birds, M. Clarke, H. Cousy, H. HeIss eds., Principles of European Insurance Contract Law, Sellier, Munich, 2009, 668 páginas. Para la elaboración de este Estudio hemos utilizado la excelente traducción de los Principles of European Insurance Contract Law (PEICL) como Principios de Derecho Europeo del Contrato de Seguro (PDECS) realizada por los profesores Juan Bataller, Paola Rodas Paredes y Nuria Pastor de 1 de noviembre de 2015. En particular, quiero dejar constancia de mi gratitud a mi compañero y amigo, Juan Bataller Grau, Catedrático de Derecho mercantil de la Universidad de Valencia y principal especialista de España en la materia dentro de nuestro país, por la generosa y desbordante ayuda prestada para la preparación de la ponencia y este estudio.

${ }_{4}$ Comunicación de la Comisión al Consejo y al Parlamento Europeo sobre un Derecho contractual europeo más coherente: un plan de acción, 12 de febrero de 2003, COM (2003) 68 final; y la Comunicación de la Comisión al Consejo y al Parlamento sobre un Derecho contractual europeo y la revisión del acervo comunitario: perspectivas para el futuro, 11 de octubre de 2004, COM (2004), 651 final.
} 
de seguro (PDECS), labor en la que -según anticipamos en la presentación de este Estudio- esta activamente implicada la SEAIDA.

\section{a) Una razón estructural: La asimetría paradójica radical de la regulación aseguradora en la UE}

En primer lugar, una razón estructural que podemos denominar como la asimetría paradójica radical de la regulación aseguradora en la UE que consiste en que, mientras la regulación del mercado de seguros ha logrado un alto nivel de armonización e incluso de unificación en lo que se refiere a la producción de los seguros, a su distribución y a la supervisión microprudencial centralizada de este mercado a través de la AESPJ/EIOPA ${ }^{5}$; no ha logrado un nivel mínimo de armonización en cuanto al contrato de seguro. Al margen de algunas referencias al contrato de seguro de vida o al seguro de defensa jurídica en la Directiva Solvencia II.

Y decimos que esta asimetría regulatoria del seguro en la UE entre el subdesarrollo de la armonización del contrato de seguro y el desarrollo de la armonización e incluso de unificación de la producción de los seguros, de su distribución y de la supervisión del mercado asegurador resulta paradójica porque la actividad aseguradora se define, precisamente, como la explotación empresarial de contratos de seguro concatenados. Basta reparar en la definiciones que hace la Ley 20/2015, de 14 de julio, de ordenación, supervisión y solvencia de las entidades aseguradoras y reaseguradoras (LOSSEAR) de su ámbito de aplicación por referencia a las "actividades de seguro directo de vida y de seguro directo distinto del seguro de vida y a las actividades de reaseguro" (art. 3) y de las provisiones técnicas diciendo que "las entidades aseguradoras y reaseguradoras computarán entre sus deudas las provisiones técnicas necesarias para reflejar todas las obligaciones derivadas de contratos de seguro y de reaseguro" (art. 69.1).

\section{b) Una razón coyuntural: El incremento del papel que el con- trato de seguro esta llamado a tener a raiz de la pandemia universal del COVID 19}

En segundo lugar, constatamos una razón coyuntural que recomienda reactivar la iniciativa de los Principios de Derecho europeo del contrato de seguro (PDECS), que reside en el incremento del papel que el contrato de seguro está llamado a tener

\footnotetext{
5 En nuestro blog financiero (ajatapia.com) pueden encontrarse multitud de entradas dedicadas a la Directiva Solvencia II, a la Directiva de Distribución de Seguros o al régimen de la AESPJ/EIOPA. Pueden consultarse también nuestros estudios sobre "El producto paneuropeo de pensiones individuales (PEPP) Reglamento (UE) 2019/1238" publicado en Relaciones transfronterizas, globalización y Derecho (Libro homenaje al Prof. Dr. José Carlos Fernández Rozas). AAVV, Ed. Civitas, Cizur Menor 2020, pp. 11451158; la "Remuneración de los administradores y del personal de las entidades aseguradoras en tiempo del coronavirus. Documentos de EIOPA", publicado en la Revista Española de Seguros (RES) n. ${ }^{\circ} 182$, SEAIDA, Madrid, (abril-junio 2020), pp. 160-176; 185; "El retraso en la aplicación de la Directiva 2016/97 de distribución de seguros y su impacto en el Derecho español" El retraso en la aplicación de la Directiva 2016/97 de distribución de seguros y su impacto en el Derecho español, La Ley Unión Europea, n. ${ }^{\circ} 59,31$ de mayo de 2018 en La Ley Unión Europea, n. ${ }^{\circ}$ 59, 31 de mayo de 2018; etc.
} 
a raíz de la pandemia universal del COVID 19 y la crisis económica derivada. En este contexto de creciente incertidumbre vital y económica, los riesgos están creciendo y se incrementarán exponencialmente en un futuro próximo y el contrato de seguro se revela como un instrumento económico y jurídico esencial para combatir la incertidumbre a costo parcial, tal y como hemos señalado en la presentación de este Estudio.

\section{La necesaria armonización de los contratos de seguro en el seno de la UE}

De lo anterior se deduce que, en este momento histórico y a la vista del grado de madurez alcanzado por la regulación armonizada del mercado asegurador en cuanto a la producción, distribución y supervisión de los seguros; parece razonable poner el foco de la atención regulatoria en armonizar la contratación aseguradora desde el momento en que los contratos de seguro son los "átomos" que integran la actividad aseguradora en su conjunto.

Este esfuerzo revitalizador de los PEDCS debe tomar en consideración el tiempo transcurrido desde su última publicación en 2016 porque, desde entonces, ha cambiado notablemente el panorama regulador de los seguros en la UE de tal manera que, por ejemplo, algunas previsiones de los PEDCS han quedado obsoletas, como las dedicadas al Derecho nacional y principios generales (Artículo 1:105) o a los mediadores de seguro (Artículo 3:101 y ss.). Ello no empecé la utilidad de estos PEDCS como punto de partida de las labores de armonización internacional.

\section{B) La noción del contrato de seguro y de sus elementos fundamentales en los PDECS}

\section{El contrato de Seguro}

La noción básica de contrato de seguro que usan los PEDCS se corresponde con la vigente en la LCS española como un contrato sinalagmático en el que las partes se intercambian prima por cobertura frente al riesgo y, eventualmente, prestación ${ }^{6}$. Así, el artículo 1:201 de los PEDCS define el contrato de seguro como "un contrato en virtud del cual una parte, el asegurador, promete a otra parte, el tomador, una cobertura frente a un riesgo concreto, a cambio de una prima".

\section{El riesgo asegurado}

Los PEDCS regulan los siguientes aspectos del riesgo asegurado?:

\footnotetext{
6 Ver Sánchez Calero, F. Ley de Contrato de Seguro. Comentarios a la Ley 50/1980, de 8 de octubre, y a sus modificaciones (dir. SÁNCHEz CALERo, F.), Editorial Aranzadi, Navarra, octubre (2010), pp. 35 y ss. y nuestra Guía del Contrato de Seguro, Colección Monografías Aranzadi, Aranzadi, Cizur Menor (2018), pp. 29 y ss.

7 Ver Sánchez Calero, F. Ley de Contrato de Seguro. Comentarios a la Ley 50/1980, de 8 de octubre, y a
} 
a) Las medidas preventivas (artículo 4:101 y ss.) diciendo que "una medida preventiva es una cláusula del contrato de seguro, sea o no establecida como una condición precedente para la responsabilidad del asegurador, que exige que, antes de que el siniestro ocurra, el tomador del seguro o el asegurado realicen o no ciertos actos".

b) La agravación del riesgo (artículo 4:201 y ss.) diciendo que "si el contrato de seguro contiene cláusulas concernientes a la agravación del riesgo asegurado, éstas no producirán efectos a menos que la agravación del riesgo en cuestión sea relevante y de un tipo especificado en el contrato de seguro". Y regulando el deber de comunicación de la agravación del riesgo y las sanciones por su incumplimiento.

c) La reducción del riesgo (artículo 4:301) con sus consecuencias en forma de que, "si existiera una reducción significativa del riesgo, el tomador del seguro podrá requerir una reducción proporcional de la prima por el tiempo restante del periodo contractual".

\section{La prima}

Los PEDCS regulan los siguientes aspectos de la prima ${ }^{8}$ :

a) Distinción entre el régimen y las consecuencias del impago de la primera prima o prima única y de las primas sucesivas (artículo 5:101 y ss.).

b) La divisibilidad de la prima (artículo 5:104).

c) El derecho al pago de la prima (artículo 5:105).

d) La prescripción de la acción para el pago de la prima por el transcurso de un año desde el momento en que se deba la prima (artículo 7:101).

\section{C) Aplicación de los PDECS}

Tal y como indicábamos anteriormente, gran parte de los principios de aplicación de los PEDCS han quedado obsoletos por el transcurso del tiempo desde su publicación y la profunda evolución de la regulación aseguradora en la UE durante dicho periodo. En todo caso, interesa destacar que se referían a los siguientes aspectos de su aplicación:

a) Su ámbito objetivo de aplicación (artículo 1:101) que abarcaba los seguros privados en general, incluyendo los seguros mutuales, pero excluía al reaseguro 9 .

b) Su aplicación dispositiva o imperativa (artículo 1:102 y ss.).

c) Su interpretación diciendo que "los PDECS deben de ser interpretados teniendo en consideración su tenor literal, contexto, finalidad y trasfondo comparativo. En particular, se deberá atender a la necesidad de promover la buena fe dentro

sus modificaciones cit., pp. 148 y ss. y nuestra Guía del Contrato de Seguro cit. pp. 26 y ss.

8 Ver Sánchez Calero, F. Ley de Contrato de Seguro. Comentarios a la Ley 50/1980, de 8 de octubre, y a sus modificaciones cit., pp. 359 y ss. y nuestra Guía del Contrato de Seguro cit. pp. 72 y ss.

9 Ver SÁnchez Calero, F. Ley de Contrato de Seguro. Comentarios a la Ley 50/1980, de 8 de octubre, y a sus modificaciones cit., pp. 1945 y ss. y nuestra Guía del Contrato de Seguro cit. pp. 143 y ss. 
del mercado asegurador, la seguridad jurídica en las relaciones contractuales, la uniformidad de aplicación y la adecuada protección de los tomadores de seguros" (artículo 1:104).

d) Los medios de protección del asegurado (artículo 1:301 y ss.) que comprendían las acciones colectivas de cesación por las denominadas entidades calificadas de consumidores y el sistema de reclamaciones extrajudiciales y mecanismos de autocomposición.

\section{CONTENIDO DE LOS PRINCIPIOS DE DERECHO EUROPEO DEL CONTRATO DE SEGURO (PDECS)}

\section{A) Disposiciones generales sobre el contrato de seguro}

Los PEDCS establecen un conjunto de disposiciones generales sobre todo tipo de contrato de seguro que afectan a los aspectos siguientes:

\section{Documentación}

a) En cuanto al idioma e interpretación de los documentos, el artículo 1:203 dice: “1) Todos los documentos suministrados por el asegurador deben de ser claros e inteligibles y deben estar redactados en el idioma en el que el contrato es negociado. (2) Cuando exista duda acerca del significado de una palabra de un documento o de una información suministrada por el asegurador, prevalecerá la interpretación más favorable al tomador del seguro, asegurado o beneficiario, según corresponda".

b) En cuanto al extremo tan relevante en la práctica aseguradora de la prueba de la recepción de los documentos, el artículo 1:204 dispone: "La carga de la prueba de que el tomador del seguro ha recibido los documentos que deben ser proporcionados por el asegurador recae en el asegurador".

c) Otro aspecto relevante es la libertad de forma de las comunicaciones porque el artículo 1:205 dispone que "sin perjuicio de lo estipulado en reglas especificas contenidas en los PDECS, las comunicaciones del solicitante, tomador del seguro, asegurado o beneficiario en relación con el contrato de seguro, no requerirán forma especifica alguna".

d) Respecto de la póliza de seguro ${ }^{10}$, el artículo 2:501 se ocupa de su contenido diciendo: "Cuando se concluya un contrato de seguro, el asegurador deberá emitir una póliza de seguro, junto con las condiciones generales del contrato si éstas no se encuentran incluidas en la póliza, conteniendo la siguiente información, si ésta es relevante: (a) el nombre y domicilio de las partes contratantes; en particular la

\footnotetext{
10 Ver Sánchez Calero, F. Ley de Contrato de Seguro. Comentarios a la Ley 50/1980, de 8 de octubre, y a sus modificaciones cit., pp. 231 y ss. y nuestra Guía del Contrato de Seguro cit. pp. 49 y ss.
} 
dirección del domicilio social y su forma jurídica, así como, en su caso, la de la sucursal de la empresa de seguros que proporcione la cobertura. (b) el nombre y domicilio del asegurado y, en caso de seguro de vida, del beneficiario y de la persona en riesgo;(...)". También se ocupan los PEDCS de los efectos de la póliza en su artículo 2:502.

\section{Conclusión}

a) Los PEDCS consagran la libertad de forma y la consensualidad del contrato de seguro ${ }^{11}$ en su artículo 2:301 que dice: "El contrato de seguro no requiere para su conclusión o prueba la forma escrita ni quedará sujeto a ningún otro requisito de forma. El contrato puede ser probado por cualquier medio, incluido el testimonio oral".

b) Contemplan también la revocación de una solicitud de seguro ${ }^{12}$ en su artículo 2:302 que dice: "Una solicitud de seguro puede ser revocada por el solicitante si la revocación llega al asegurador antes de que el solicitante reciba la aceptación del asegurador".

c) Conceden un periodo de reflexión al tomador del seguro cuando su artículo 2:303 dispone: "El tomador del seguro podrá desistir del contrato a través de una comunicación escrita dentro de las dos semanas siguientes a la recepción de la aceptación o, si ésta fuera posterior, a la entrega de los documentos contemplados en el artículo 2:501".

d) Tratan de las cláusulas abusivas del contrato de seguro ${ }^{13}$ proyectando los criterios de la Directiva general de 1983 sobre este tipos de cláusulas cuando el artículo 2:304 dice: “(1) Una cláusula que no haya sido negociada individualmente no será vinculante para el tomador del seguro, el asegurado o el beneficiario si, pese a las exigencias de la buena fe, causan un significativo desequilibrio en detrimento de sus derechos y obligaciones derivados del contrato, considerando la naturaleza del contrato de seguro, los demás términos del contrato y las circunstancias en el momento en que el contrato fue concluido. (2) El contrato seguirá siendo vinculante para las partes, si éste puede subsistir sin las cláusulas abusivas. Si no es posible, la cláusula abusiva será sustituida por otra que las partes podrían haber acordado razonablemente de haber conocido el carácter abusivo de la cláusula.(3) Este artículo es aplicable a las estipulaciones que restrinjan o modifiquen la cobertura, pero no se aplicará: (a) a la adecuación del valor de la cobertura y de la prima; ni (b) a las cláusulas que contengan la descripción esencial de la cobertura concertada o la prima acordada, siempre que las cláusulas estén redactadas en un lenguaje sencillo e inteligible.(4) Se considerará que una cláusula no se ha negociado individualmente cuando haya sido

\footnotetext{
11 Ver Sánchez Calero, F. Ley de Contrato de Seguro. Comentarios a la Ley 50/1980, de 8 de octubre, y a sus modificaciones cit., pp. 165 y ss. y nuestra Guía del Contrato de Seguro cit. pp. 35 y ss.

12 Ver Sánchez Calero, F. Ley de Contrato de Seguro. Comentarios a la Ley 50/1980, de 8 de octubre, y a sus modificaciones cit., pp. 183 y ss. y nuestra Guía del Contrato de Seguro cit. pp. 49 y ss.

13 Ver Sánchez Calero, F. Ley de Contrato de Seguro. Comentarios a la Ley 50/1980, de 8 de octubre, y a sus modificaciones cit., pp. 105 y ss. y nuestra Guía del Contrato de Seguro cit. pp. 35 y ss.
} 
redactado previamente y el tomador del seguro, consecuentemente, no haya podido influir sobre su contenido, particularmente en el caso de los contratos de adhesión. El hecho de que ciertos elementos de una cláusula o que una cláusula aislada se haya negociado individualmente no excluirá la aplicación del presente artículo al resto del contrato si la apreciación global lleva a la conclusión de que se trata de un contrato de adhesión. El asegurador que afirme que una cláusula tipo se ha negociado individualmente asumirá plenamente la carga de la prueba".

\section{Duración}

a) Afectan a este aspecto de la duración del contrato de seguro determinadas definiciones adicionales contenidas en su artículo 1:202 como son la de "Período contractual" como "el período de obligaciones contractuales que comienza con la perfección del contrato y termina cuando transcurre el período de tiempo acordado"; "Período asegurado" como "el período durante el cual se debe la prima de acuerdo con lo dispuesto por las partes" o "Período de responsabilidad" como "el período de cobertura".

b) En segundo lugar, los PEDCS tratan de la eventual cobertura retroactiva en su artículo 2:401 y de la cobertura preliminar en su artículo 2:402 y ss.

c) Siguen regulando la duración del contrato de seguro en sentido estricto ${ }^{14}$ los PEDCS en su artículo 2:601 que dice: “(1) La duración del contrato de seguro será de un año. Las partes podrán acordar un período diferente en función de la naturaleza del riesgo. (2) El párrafo 1 no será de aplicación a los seguros de personas".

d) Y el artículo 2:602 se refiere a la prórroga diciendo que “(1) Una vez transcurrido el período de un año señalado en el artículo 2:601, el contrato se renovara automáticamente a menos que: (a) el asegurador haya comunicado por escrito lo contrario, con al menos un mes de antelación a la fecha de expiración del periodo contractual, señalando las razones de esta decisión; o (b) el tomador del seguro haya comunicado por escrito lo contrario, y como muy tarde, hasta el día en el que el período contractual expira o dentro del mes siguiente a la recepción del recibo de la prima, si esta fecha es posterior. En este último caso, el período de un mes sólo empezara a correr si ha sido claramente resaltado con letra negrita en el recibo. (2) A los efectos del párrafo 1 (b) la notificación será tenida por entregada en cuanto haya sido enviada".

\section{Modificación de cláusulas y condiciones}

El artículo 2:603 de los PEDCS regula el régimen de la modificación de las cláusulas y condiciones del contrato de seguro diciendo: “(1) En un contrato de seguro sujeto a prórroga automática de acuerdo con lo establecido en el artículo 2:602, una cláusula

\footnotetext{
14 Ver Sánchez Calero, F. Ley de Contrato de Seguro. Comentarios a la Ley 50/1980, de 8 de octubre, y a sus modificaciones cit., pp. 535 y ss. y nuestra Guía del Contrato de Seguro cit. pp. 31 y ss.
} 
que permita al asegurador modificar la prima o cualquier otra cláusula o condición del contrato será ineficaz a menos que: (a) las modificaciones sólo tengan efecto a partir de la siguiente prórroga; (b) el asegurador haya enviado al tomador del seguro comunicación por escrito de la modificación como mínimo un mes antes de la expiración del periodo contractual actual; y (c) la comunicación informe al tomador del seguro acerca de su derecho a dar por finalizado el contrato y de las consecuencias si dicho derecho no es ejercido.(...)".

\section{Finalización tras el acaecimiento del siniestro}

El artículo 2:604 de los PEDCS establece la finalización del contrato de seguro tras el acaecimiento del siniestro disponiendo que: "(1) Una cláusula que prevea la finalización del contrato después de producirse el siniestro no será válida a menos que: (a) otorgue el derecho de finalización a ambas partes; y (b) la póliza no sea una de seguros de personas. (2) Tanto la cláusula de finalización como el ejercicio de cualquier derecho de finalización deberán ser razonables. (3) Cualquier derecho a la finalización expirará si la parte en cuestión no ha comunicado por escrito la finalización a la otra parte, dentro de los dos meses siguientes a haber tenido conocimiento del siniestro.(4) La cobertura del seguro terminará dos semanas después de la comunicación establecida en el párrafo 3".

\section{Deberes del tomador}

a) Deber de información precontractual del solicitante ${ }^{15}$ : El artículo 2:101 de los PEDCS establece este deber de información diciendo: “(1) En el momento de concluir el contrato, el solicitante informará al asegurador de las circunstancias que el solicitante conozca o debería conocer, y que sean objeto de preguntas claras y precisas por parte del asegurador. (2) Las circunstancias a las que hace referencia el párrafo 1 incluyen aquellas que la persona que sea asegurada conocía o debería haber conocido". Después detalla las consecuencias del incumplimiento negligente o doloso de este deber (artículo 2:102 y ss.).

b) Comunicación del siniestro"16: El artículo 6:101 de los PEDCS establece que "(1) El tomador del seguro, el asegurado o el beneficiario, según proceda, comunicará al asegurador el acaecimiento del siniestro siempre que la persona obligada a comunicar tuviera o hubiera debido tener conocimiento de la cobertura del seguro y del acaecimiento del siniestro. Será válida la comunicación efectuada por un tercero. (2) La comunicación se realizará sin demoras injustificadas. Será eficaz desde su envío. Si el contrato exigiera que la comunicación se realice dentro de un período de tiempo limitado, dicho período deberá ser razonable y en cualquier caso no inferior

\footnotetext{
15 Ver Sánchez Calero, F., Ley de Contrato de Seguro. Comentarios a la Ley 50/1980, de 8 de octubre, y a sus modificaciones cit., pp. 279 y ss. y nuestra Guía del Contrato de Seguro cit. pp. 61 y ss.

16 Ver Sánchez Calero, F. Ley de Contrato de Seguro. Comentarios a la Ley 50/1980, de 8 de octubre, y a sus modificaciones cit., pp. 399 y ss. y nuestra Guía del Contrato de Seguro cit. pp. 76 y ss.
} 
a cinco días. (3) La prestación del asegurador se reducirá en la medida en que el asegurador demuestre que ha resultado perjudicado por una demora injustificada".

c) Cooperación durante la liquidación: El artículo 6:102 de los PEDCS dispone que “(1) El tomador del seguro, el asegurado, o el beneficiario, según proceda, cooperará con el asegurador en el esclarecimiento del siniestro, atendiendo sus peticiones razonables, y en particular a las relativas a: información acerca de las causas y efectos del siniestro; - documentación u otro tipo de evidencias sobre el siniestro; acceso a los lugares relacionados con el siniestro. (2) En caso de incumplimiento de cualquiera de los puntos señalados en el párrafo 1 y sin perjuicio de lo establecido en el párrafo 3, la prestación del asegurador se reducirá en la medida en que el asegurador pruebe que ha resultado perjudicado por el incumplimiento.(3) En caso de que el incumplimiento de cualquiera de los puntos señalados en el párrafo 1 haya sido cometido con intención de causar perjuicio o con negligencia y conocimiento de que dicho perjuicio sería probable, el asegurador quedará liberado de su prestación".

\section{Deberes del asegurador}

a) Entrega de la documentación precontractual: El artículo 2:201 de los PEDCS regula este primer deber del asegurador diciendo: “(1) El asegurador proporcionará al solicitante una copia de las estipulaciones contractuales propuestas, así como un documento que incluya, si es relevante, la siguiente información: (...) (2) En la medida de lo posible, esta información deberá proveerse al solicitante con la antelación suficiente para que éste pueda considerar si concluye o no el contrato. (3) Cuando el solicitante solicite la cobertura de un seguro basado en un formulario y/o cuestionario proporcionado por el asegurador, el asegurador proveerá al solicitante de una copia de todos los documentos completados".

b) Deber de advertencia sobre inconsistencias en la cobertura ${ }^{17}$ : El artículo 2:202 de los PEDCS establece a este respecto: “(1) En el momento de formalizar el contrato, el asegurador deberá advertir al solicitante de cualquier inconsistencia entre la cobertura ofrecida y las necesidades del solicitante que sean o debieran ser conocidas por el asegurador, considerando las circunstancias y la forma de contratación y, en particular, si el solicitante estuvo asistido por un mediador independiente".

c) Deber de advertencia sobre el comienzo de la cobertura: El artículo 2:203 establece: "Si el solicitante, razonable pero equivocadamente, cree que la cobertura comienza desde el momento en que se envía la solicitud, y el asegurador conoce o debería haber conocido dicha suposición, el asegurador deberá advertir inmediatamente al solicitante de que la cobertura comenzará cuando el contrato se concluya y, si es aplicable, cuando la primera prima haya sido pagada, a menos que se otorgue

\footnotetext{
17 Ver la entrada de nuestro blog financiero de 22 de septiembre de 2020 sobre "Las sorpresas que dan las cláusulas sorprendentes en los contratos de seguro y sus consecuencias. A propósito de la Sentencia del Pleno de la Sala Primera de lo Civil del Tribunal Supremo 421/2020, de 14 de julio. Seguro de responsabilidad civil de administradores y directivos de sociedades (seguro de D\&O). Cobertura accesoria de defensa jurídica" y las demás entradas sobre las cláusulas sorprendentes citadas en ella.
} 
cobertura preliminar. Si el asegurador incumple el deber de advertencia será responsable de acuerdo con el artículo 2:202 párrafo 2 (a)".

d) Deberes de información postcontractual del asegurador: Los artículos 2:701 y ss. diferencian entre el deber general de información del asegurador a lo largo del período contractual sobre todo cambio concerniente a su nombre o denominación social, domicilio, forma jurídica, domicilio de su oficina principal y de la agencia o sucursal con la que celebró el contrato y la información adicional a suministrar bajo requerimiento del tomador sobre todos los temas relevantes relativos a la ejecución del contrato, de forma razonable o nuevas cláusulas estándar ofrecidas por el asegurador para los contratos de seguro del mismo tipo que los concluidos con el tomador del seguro.

e) Deber de pago de la prestación ${ }^{18}$ : El artículo 6:103 de los PEDCS regula este deber esencial del asegurador comenzando por la aceptación de la reclamación al decir que “(1) El asegurador deberá seguir todos los pasos razonables para resolver rápidamente todas las reclamaciones. (2) La reclamación será tenida por aceptada a menos que el asegurador la rechace o manifieste su discrepancia respecto a su aceptación a través de comunicación escrita, especificando las causas de su decisión dentro del mes siguiente a la recepción de todos los documentos relevantes y demás información". Después, los PEDCS regulan el momento de cumplimiento señalando que: “(1) Cuando se haya aceptado una reclamación, el asegurador deberá pagar o suministrar los servicios prometidos, según corresponda, sin demora injustificada. (2) Incluso cuando el valor total de la reclamación no pudiera ser cuantificado, pero el reclamante tenga derecho al menos a una parte de la reclamación, dicha parte será pagada o satisfecha sin demora injustificada.(3) El pago de la indemnización, ya sea según el párrafo 1 ó 2 , se realizará no más tarde de una semana después de la aceptación y cuantificación de la reclamación, o de una parte de ella, según corresponda" (artículo 6:104).

Más adelante, los PEDCS establecen el régimen de la mora del asegurador ${ }^{19}$ con un interés moratorio que desincentive el retraso al decir: "(1) Si no se satisface la indemnización según lo dispuesto en el artículo 6:104, el reclamante tendrá derecho al cobro de intereses sobre esa suma, desde el momento en que fuera pagadera hasta el momento efectivo del pago, y el interés será igual al aplicado por el Banco Central Europeo a su más reciente operación principal de refinanciación efectuada antes del primer día natural del semestre en cuestión, más ocho puntos porcentuales.(2) El reclamante tendrá derecho a que se cubran los daños por las pérdidas adicionales ocasionadas por la demora en el pago de la indemnización" (artículo 6:105).

Por último, la acción para reclamar el pago de la prestación asegurada, prescribirá en el plazo de tres años a contar desde que el asegurador tome o se pueda presumir que ha tomado una decisión acerca de la reclamación de conformidad con lo señalado en el artículo 6:103. En todo caso, sin embargo, la acción prescribirá una vez transcurridos

\footnotetext{
18 Ver Sánchez Calero, F. Ley de Contrato de Seguro. Comentarios a la Ley 50/1980, de 8 de octubre, y a sus modificaciones cit., pp. 428 y ss. y nuestra Guía del Contrato de Seguro cit. pp. 82 y ss.

19 Ver Sánchez Calero, F. Ley de Contrato de Seguro. Comentarios a la Ley 50/1980, de 8 de octubre, y a sus modificaciones cit., pp. 466 y ss. y nuestra Guía del Contrato de Seguro cit. pp. 83 y ss.
} 
diez años desde el acaecimiento del siniestro, excepto en el caso de los seguros de vida en los cuales el período relevante será de 30 año (artículo 7:102).

\section{Contratos de seguro de grupo}

La Sexta parte de los PEDCS (artículo 18:101 y ss.) establece los principios aplicables a los "Contratos de seguro de grupo"20 que define -en su artículo 1:201- como "contratos entre un asegurador y un organizador de un grupo que en beneficio de los miembros que tienen una relación común con el organizador. Un contrato de seguro de grupo podrá cubrir también a los familiares de los miembros del grupo". Estos principios afectan a tres aspectos:

a) Las disposiciones generales del seguro de grupo que tratan de su ámbito y del deber de diligencia del organizador de grupo (artículo 18:101 y ss.).

b) Las disposiciones especiales sobre los seguros de grupo accesorios que son aquellos "contratos de seguro de grupo por los que los miembros pertenecientes al grupo están automáticamente asegurados por el mero hecho de pertenecer al grupo y sin posibilidad de renunciar al seguro" artículo 1:201), de los que se establecen los deberes de información, la finalización por el asegurador y el derecho de continuación de la cobertura en los seguros de vida de grupo (18:202 y ss.).

h.2) Las disposiciones especiales sobre los seguros de grupo electivos que son aquellos "contratos de seguro de grupo por los que los miembros pertenecientes al grupo están cubiertos como consecuencia de su previa solicitud del seguro o por su falta de renuncia" (artículo 1:201). De ellos se regulan determinadas generalidades, la alteración de sus términos y condiciones y la continuación de la cobertura (artículo 18:301 y ss.).

\section{B) Seguros de daños}

\section{Noción}

Los PEDCS optan por una denominación de los seguros de daños como "seguros indemnizatorios" de una forma que nos parece equívoca y más adecuada a la clasificación jurídico publica de los ramos de seguro. A tal efecto, debemos recordar que la clasificación jurídico-privada de contratos de seguro contenida en el título II de la LCS española regula los seguros contra daños ${ }^{21}$-también llamados de indemnización efectiva o de cobertura concreta de necesidad- estableciendo unas disposiciones generales sobre los mismos y unas normas particulares sobre los seguros de incendios, contra el robo, de transportes terrestres, de lucro cesante, de caución, de crédito, de responsabilidad civil, de defensa jurídica y sobre el reaseguro.

\footnotetext{
20 Ver Sánchez Calero, F. Ley de Contrato de Seguro. Comentarios a la Ley 50/1980, de 8 de octubre, y a sus modificaciones cit., pp. 2054 y ss. y nuestra Guía del Contrato de Seguro cit. pp. 149 y ss.

21 Ver SÁnchez Calero, F. Ley de Contrato de Seguro. Comentarios a la Ley 50/1980, de 8 de octubre, y a sus modificaciones cit., pp. 589 y ss. y nuestra Guía del Contrato de Seguro cit. pp. 93 y ss.
} 
En todo caso, procede reseñar que los PEDCS definen el seguro de daños como "un seguro en virtud del cual el asegurador se obliga a indemnizar los daños sufridos en caso de que ocurra el siniestro" (artículo 1:201) y dedican dos apartados a su regulación, de los que nos ocupamos seguidamente.

\section{Las disposiciones generales aplicables a todos los seguros indemnizatorios}

Abarcan los siguientes aspectos:

a) La suma asegurada o indemnización máxima ${ }^{22}$ diciendo: “(1) El asegurador no estará obligado a pagar más de la cantidad necesaria para indemnizar las pérdidas sufridas realmente por el asegurado. (2) Una cláusula que determine el valor estimado del bien asegurado será válida incluso si dicho valor excede del valor actual del bien asegurado, siempre que no existiera fraude o engaño por parte del tomador del seguro o del asegurado al tiempo de acordar dicho valor" (artículo 8:101)

b) La relación entre el valor del interés y la suma asegurada diferenciando las hipótesis básicas del:

b.1) Infraseguro ${ }^{23}$, diciendo en el artículo 8:102: “(1) El asegurador responderá de las pérdidas hasta el monto máximo de la suma asegurada incluso si la misma es inferior al valor del bien asegurado en el momento en que ocurra el siniestro. (2) Sin embargo, cuando el asegurador ofrezca cobertura de acuerdo con lo establecido en el párrafo 1, podrá alternativamente ofrecerla con la condición de que la indemnización a pagar estará limitada proporcionalmente al valor que tenga el bien asegurado en el momento de materializarse el daño. En dicho caso, además, los gastos de salvamento, definidos en el artículo 9:102, serán satisfechos en la misma proporción".

b.2) Sobreseguro ${ }^{24}$, respecto del cual el artículo 8:103 dice: “(1) Si la suma asegurada excede de la pérdida total máxima del seguro, cualquiera de las partes podrá exigir la reducción de la suma asegurada y la correspondiente reducción de la prima por el periodo restante. (2) Si las partes no llegaran a un acuerdo sobre dicha reducción dentro del mes siguiente al requerimiento, cualquiera de las partes podrá finalizar el contrato".

c) El seguro múltiple o cumulativo ${ }^{25}$ diciendo: "(1) Cuando el mismo interés esté asegurado separadamente por más de un asegurador, el asegurado podrá pedir

\footnotetext{
22 Cfr. art. 27 LCS y ver Sánchez Calero, F. Ley de Contrato de Seguro. Comentarios a la Ley 50/1980, de 8 de octubre, y a sus modificaciones cit., pp. 626 y ss. y nuestra Guía del Contrato de Seguro cit., pp. 95. ${ }_{23}$ Cfr. art. 30 LCS y ver Sánchez Calero, F. Ley de Contrato de Seguro. Comentarios a la Ley 50/1980, de 8 de octubre, y a sus modificaciones cit., pp. 665 y ss. y nuestra Guía del Contrato de Seguro cit., pp. 96.

${ }^{24}$ Cfr. art. 31 LCS y ver Sánchez Calero, F. Ley de Contrato de Seguro. Comentarios a la Ley 50/1980, de 8 de octubre, y a sus modificaciones cit., pp. 681 y ss. y nuestra Guía del Contrato de Seguro cit., pp. 96.

${ }_{25}$ Cfr. art. 32 LCS y ver SÁnchez Calero, F. Ley de Contrato de Seguro. Comentarios a la Ley 50/1980, de 8 de octubre, y a sus modificaciones cit., pp. 695 y ss. y nuestra Guía del Contrato de Seguro cit., pp. 97 y 98 .
} 
la indemnización a uno o varios de los aseguradores hasta alcanzar la cantidad necesaria para cubrir las pérdidas reales sufridas por el asegurado. (2) El asegurador al que se le solicite, pagará la suma asegurada en su póliza, junto con los gastos de salvamento, sin perjuicio de su derecho de regreso sobre los otros aseguradores. (3) Entre los aseguradores los derechos y obligaciones referidos en el párrafo 2 serán proporcionales a los que les corresponda por separado ante el asegurado" (artículo 8:104).

d) La provocación del daño ${ }^{26}$ señalando al respecto: “(1) Ni el tomador del seguro ni el asegurado, según sea el caso, tendrá derecho a la indemnización si la pérdida fuera consecuencia de un acto u omisión por su parte realizado con la intención de provocar el daño, o de forma negligente y con conocimiento de que probablemente se causaría el daño. (2) Sin perjuicio del establecimiento de una cláusula específica en la póliza que establezca la reducción de la indemnización en función de su grado de culpa, el tomador del seguro o asegurado, según sea el caso, tendrá derecho a la indemnización respecto a cualquier pérdida causada por una acción u omisión negligente por su parte. (3) Para el caso de lo establecido en los párrafos 1 y 2, provocar daños incluye la omisión de evitar o atenuar el daño” (artículo 9:101).

e) Los gastos de salvamento ${ }^{27}$ diciendo: “(1) El asegurador reembolsará los costes o daños en los que incurra el tomador del seguro o el asegurado al tomar medidas destinadas a la atenuación del daño asegurado, si dichas medidas hubieran sido razonables a la luz de las circunstancias existentes, incluso si no hubieran podido efectivamente evitar la pérdida. (2) El asegurador indemnizará al tomador del seguro o al asegurado, según sea el caso, por las medidas tomadas de acuerdo con el párrafo 1, incluso si la cantidad a pagar, junto con la indemnización del daño asegurado, excede de la suma asegurada" (artículo 9:102).

f) El derecho a la subrogación del asegurador ${ }^{28}$ diciendo que este "podrá ejercer su derecho a subrogarse contra cualquier tercero responsable del daño, en la medida en que haya indemnizado al asegurado. (2) En la medida en que la renuncia del asegurado a su derecho contra el tercero perjudique el derecho a subrogarse del asegurador, el asegurado perderá su derecho a la indemnización por el daño en cuestión. (3) El asegurador no podrá ejercer su derecho a la subrogación contra un miembro de la familia del tomador del seguro o del asegurado, una persona con una relación social equivalente con el tomador del seguro o asegurado, o un empleado del tomador del seguro o asegurado, excepto cuando pruebe que la pérdida fue causada por dicha persona de forma intencionada o con negligencia y conocimiento de que

\footnotetext{
${ }^{26}$ Cfr. art. 19 LCS y ver SÁnchez Calero, F. Ley de Contrato de Seguro. Comentarios a la Ley 50/1980, de 8 de octubre, y a sus modificaciones cit., pp. 443 y ss. y nuestra Guía del Contrato de Seguro cit., pp. 83. 27 Cfr. art. 17 LCS y ver Sánchez Calero, F. Ley de Contrato de Seguro. Comentarios a la Ley 50/1980, de 8 de octubre, y a sus modificaciones cit., pp. 413 y ss. y nuestra Guía del Contrato de Seguro cit., pp. 77.83

28 Cfr. art. 43 LCS y ver SÁnchez Calero, F. Ley de Contrato de Seguro. Comentarios a la Ley 50/1980, de 8 de octubre, y a sus modificaciones cit., pp. 948 y ss. y nuestra Guía del Contrato de Seguro cit., pp. 103 y ss.
} 
probablemente se produciría el daño.(4) El asegurador no podrá ejercer su derecho a la subrogación en perjuicio del asegurado" (artículo 10:101).

g) La eventual falta de riesgo asegurado estableciendo que "(1) No se devengará prima alguna si el riesgo asegurado no existe en el momento de la conclusión del contrato o en cualquier momento a lo largo de la duración del período asegurado. Sin embargo, el asegurador tendrá derecho a una suma razonable por los gastos en que incurra. (2) Si el riesgo asegurado deja de existir durante el período asegurado, el contrato se tendrá por finalizado en el momento de la comunicación de este hecho al asegurador" (artículo 12:101).

h) Los efectos de la transmisión de la propiedad de la cosa asegurada ${ }^{29}$ (artículo 12:102).

\section{Las disposiciones especiales sobre el seguro de responsabilidad civil}

El seguro de responsabilidad civil ${ }^{30}$ se define como "un seguro en virtud del cual el riesgo es la exposición del asegurado a responsabilidad civil respecto de la víctima" (artículo 1:201) que, en un seguro de responsabilidad civil, significa "la persona por cuya muerte, daño personal o daño material es responsable civilmente el asegurado" (artículo 1:202).

Los PEDCS regulan los aspectos siguientes del seguro de responsabilidad civil:

a) Los gastos de defensa ${ }^{31}$ que el asegurador deberá abonar (artículo 14:101).

b) La protección de la víctima en el sentido establecido en el artículo 14:102 que dice: "Salvo que la víctima otorgue su consentimiento por escrito, su posición no se verá afectada por ningún acuerdo alcanzado en relación a la reclamación del seguro por parte del tomador del seguro bajo la póliza o entre el asegurador y el asegurado, bien sea por acuerdo, exención, pago o cualquier otro acto equivalente".

c) Las consecuencias de la provocación o causación de la pérdida por el tomador del seguro o el asegurado en el sentido establecido en el artículo 14:103 que dispone: “(1) Ni el tomador del seguro ni el asegurado, según sea el caso, tendrán derecho a indemnización en el caso en que la pérdida fuera causada por su acción u omisión, mediando la intención de causar la pérdida. Tampoco tendrán derecho a indemnización si incumplen las instrucciones especificas dadas por el asegurador con posterioridad

\footnotetext{
${ }^{29}$ Cfr. art. 34 LCS y ver Sánchez Calero, F. Ley de Contrato de Seguro. Comentarios a la Ley 50/1980, de 8 de octubre, y a sus modificaciones cit., pp. 744 y ss. y nuestra Guía del Contrato de Seguro cit., pp. 99 y ss.

${ }^{30}$ Cfr. art. 73 LCS y ver Sánchez Calero, F. Ley de Contrato de Seguro. Comentarios a la Ley 50/1980, de 8 de octubre, y a sus modificaciones cit., pp. 1589 y ss. y nuestra Guía del Contrato de Seguro cit., pp. 119 y ss.

31 Cfr. art. 74 LCS y ver Sánchez Calero, F. Ley de Contrato de Seguro. Comentarios a la Ley 50/1980, de 8 de octubre, y a sus modificaciones cit., pp. 1662 y ss. y nuestra Guía del Contrato de Seguro cit., pp. 135 .
} 
a la pérdida, cuando dicho incumplimiento sea negligente y con conocimiento de la probable agravación de la pérdida. (2) A los efectos del párrafo 1, causación de la pérdida incluye la falta de acción para evitar o mitigar la pérdida. (3) Sin perjuicio de la existencia de una cláusula específica en la póliza que prevea la reducción de la cuantía del seguro en relación al grado de culpa por su parte, el tomador del seguro o asegurado, según sea el caso, tendrá derecho a indemnización respecto de cualquier pérdida causada por el incumplimiento negligente de las especificas instrucciones dadas por asegurador con posterioridad a la producción de la pérdida".

d) Las consecuencias del conocimiento, aceptación o satisfacción de su responsabilidad por el tomador del seguro o asegurado en el sentido establecido en el artículo 14:104 que establece: "(1) Cualquier cláusula en el contrato de seguro que exima al asegurador de sus obligaciones en caso de que el tomador del seguro o asegurado, según sea el caso, acepte o satisfaga la reclamación de la víctima se dejará sin efectos. (2) Salvo consentimiento, el asegurador no quedará vinculado por ningún acuerdo".

e) La bonificación de la prima en función de la baja siniestralidad previa en el sentido establecido en el artículo 14:106 que, regulando el "Bono por falta de reclamación / Sistemas bonus-malus" dispone: "(1) El tomador de la póliza tendrá el derecho de solicitar en cualquier momento el documento que contenga su historial de reclamaciones de los últimos cinco años. (2) Si el asegurador asocia el cálculo de la prima u otras condiciones al número o cantidad de reclamaciones abonadas bajo la póliza, deberá tener en consideración el historial de reclamaciones de los últimos cinco años del tomador de seguro con otras compañias aseguradoras".

f) La noción de siniestro asegurado y la aceptación de la delimitación temporal de la cobertura por referencia a la reclamación ("claims made basis") 32 cuando el artículo 14:107 establece que el siniestro asegurado es "aquél hecho que da lugar a la responsabilidad del asegurado y que acaece durante el periodo de responsabilidad del contrato de seguro, salvo que las partes contraten el seguro con finalidad comercial o profesional y definan el siniestro asegurado con referencia a otros criterios, como la reclamación realizada por la víctima. (2) Cuando las partes contratantes definan el siniestro asegurado con referencia a la reclamación efectuada por la víctima, la cobertura se otorgará respecto de las reclamaciones hechas dentro del periodo de responsabilidad o subsiguientes periodos no inferiores a cinco años basados en hechos acaecidos durante la vigencia del periodo de responsabilidad. El contrato de seguro podrá excluir la cobertura cuando, al momento de formalizar el contrato, el solicitante conociera o debiera conocer las circunstancias que previsiblemente hubieran dado lugar a las reclamaciones".

g) En reconocimiento - limitado a determinados supuestos- de las reclamaciones y acciones directas del tercer perjudicado y la limitación de las excepciones oponibles por el asegurador ${ }^{33}$ cuando el artículo 15:101 dice: “(1) La víctima tendrá derecho de

\footnotetext{
32 Cfr. art. 73 LCS y ver SÁnchez Calero, F. Ley de Contrato de Seguro. Comentarios a la Ley 50/1980, de 8 de octubre, y a sus modificaciones cit., pp. 1642 y ss. y nuestra Guía del Contrato de Seguro cit., pp. 123 y ss.

33 Cfr. art. 76 LCS y ver Sánchez Calero, F. Ley de Contrato de Seguro. Comentarios a la Ley 50/1980,
} 
reclamación directa contra el asegurador en la medida en que tomador del seguro o el asegurado, según sea el caso, sea responsable, siempre y cuando: (a) El contrato de seguro sea obligatorio, o (b) El tomador del seguro o el asegurado sea insolvente, o (c) El tomador del seguro o el asegurado se encuentre en liquidación, o (d) La víctima haya sufrido un daño personal, o (e) La ley que rija la responsabilidad contemple la acción directa. (2) En su condición de agente, el asegurador alegará todas las excepciones a su disposición bajo el contrato de seguro, salvo prohibición de las previsiones especificas que hagan el seguro obligatorio. No obstante, el asegurador no tendrá derecho a alegar ninguna excepción basada en la conducta del tomador del seguro y/o el asegurado con posterioridad a la pérdida".

h) El deber de información a la víctima por el tomador del seguro y el asegurado de la existencia del seguro cuando el artículo 15:102 dispone: “(2) El asegurador notificará por escrito al tomador del seguro sobre cualquier reclamación efectuada contra él sin demora injustificada y, como muy tarde, dentro de las dos semanas siguientes a la recepción de la reclamación. Si el asegurador incumple dicha obligación, el pago o conocimiento de la deuda hacia la víctima no afectará los derechos del tomador del seguro. (3) Si el tomador del seguro no facilita al asegurador sobre la información relativa al siniestro asegurado dentro del plazo de un mes desde la recepción de la notificación mencionada en el párrafo 2, se considerará que el tomador del seguro se allana con la reclamación realizada por el asegurador. Esta norma también será de aplicación para los asegurados que hayan recibido dicha notificación en tiempo".

i) La prescripción de la acción contra el asegurador, presentada por el asegurado o por la propia víctima, cuando la acción de la víctima contra el asegurado haya prescrito con la cautela de que "el periodo de prescripción por una reclamación realizada por la víctima contra el asegurado quedará suspendido desde el momento en que el asegurado tenga conocimiento de la existencia de reclamación directa contra el asegurador y hasta que la misma sea satisfecha o inequívocamente rechazada por el asegurador, en su caso" (artículo 15:104).

j) El seguro obligatorio ${ }^{34}$ que es "el seguro contratado como consecuencia de una obligación impuesta por ley u otra norma jurídica" (artículo 1:202 Definiciones adicionales) añadiendo que, en estos casos, "el contrato de seguro no eximirá de la obligación de aseguramiento, salvo que cumpla con las especificas provisiones que imponga dicha obligación" (artículo 16:101).

\section{C) Seguros de personas}

\section{Noción}

Los PEDCS optan por denominar los seguros de personas como "seguros de sumas", denominación esta que nos parece equívoca y más adecuada a la clasificación jurídico

de 8 de octubre, y a sus modificaciones cit., pp. 1721 y ss. y nuestra Guía del Contrato de Seguro cit., pp. 127 y ss.

34 Cfr. Disp. Ad. Segunda LOSSEAR y v. nuestra Guía del Contrato de Seguro cit., pp. 136. 
publica de los ramos de seguro. A tal efecto, debemos recordar que la clasificación jurídico-privada de contratos de seguro contenida en el título III de la LCS española -con la finalidad de regular la estructura contractual imperativa y, en particular, los derechos y obligaciones que incumben a las partes de contrato de seguro- distingue los seguros de personas ${ }^{35}$-también llamados de indemnización presunta o de cobertura abstracta de necesidad- a los que dedica una serie de disposiciones comunes y otras específicas para los seguros sobre la vida, de accidentes, de enfermedad y asistencia sanitaria y de decesos y dependencia (ver nuestra Guía del Contrato de Seguro cit., p. 30).

Los PEDCS definen el "Seguro de sumas" como "un seguro en virtud del cual el asegurador se obliga a pagar una suma fija de dinero en caso de que ocurra el siniestro" (artículo 1:201).

\section{Disposiciones generales de los seguros de sumas o de personas}

A diferencia de lo que sucede en nuestra LCS, que dedica una serie de disposiciones comunes a los seguros de personas en la Sección $1^{\text {a }}$ de su título III; los PEDCS limitan esta normativa común a predicar su admisibilidad exclusivamente en los casos de seguros de accidentes, asistencia sanitaria, vida, matrimonio, nacimiento u otros seguros de personas (artículo 13:101).

\section{Disposiciones especiales del seguro sobre la vida}

Los PEDCS definen el "seguro de vida" como "un seguro en virtud del cual la obligación del asegurador o el pago de la prima dependen de un siniestro determinado exclusivamente en base a la muerte o supervivencia de la persona en riesgo" y la "persona en riesgo" como "la persona sobre cuya vida, salud, integridad o estatus es suscrito un seguro" (artículo 1:201).

Los PEDCS se ocupan de los siguientes aspectos de este seguro de vida:

a) La posibilidad de contratar un seguro sobre la vida de un tercero cuando establecen, en su artículo 17:101: "Un contrato de seguro sobre la vida de un tercero distinto al tomador del seguro será inválido, salvo que la persona en riesgo otorgue su consentimiento por escrito y lo firme. Cualquier cambio sustancial en el contrato, incluido el cambio del beneficiario, un aumento de la suma asegurada y el cambio de la duración del contrato se dejará sin efecto si no existe dicho consentimiento. También será de aplicación en caso de cesión o gravamen del contrato de seguro o del derecho a la prestación".

\footnotetext{
35 Ver Sánchez Calero, F., Ley de Contrato de Seguro. Comentarios a la Ley 50/1980, de 8 de octubre, y a sus modificaciones cit., pp. 2029 y ss. y nuestra Guía del Contrato de Seguro cit., pp. 147 y ss.

${ }^{36}$ Cfr. art. 83 y ss. LCS y ver SÁnChez CAlero, F., Ley de Contrato de Seguro. Comentarios a la Ley 50/1980, de 8 de octubre, y a sus modificaciones cit., pp. 2136 y ss. y nuestra Guía del Contrato de Seguro cit., pp. 155 y ss.
} 
b) La posición del beneficiario de la prestación ${ }^{37}$ en dos sentidos:

b.1) El régimen de su designación y revocación cuando el artículo 17:102 dice: “(1) El tomador del seguro designará uno o más beneficiarios de la prestación y podrá modificar o revocar dicha designación, salvo que esta se haya declarado irrevocable. La designación, cambio o revocación, salvo contemplada en testamento, deberá realizarse por escrito y enviada al asegurador. (2) El derecho a designar, modificar o revocar la designación finalizará con la muerte del tomador del seguro o el acaecimiento del siniestro asegurado, cualquier que sea anterior. (3) El tomador del seguro o sus herederos, según sea el caso, se considerarán los beneficiarios de la prestación si (a) El tomador del seguro no ha designado beneficiario o (b) La designación de un beneficiario ha sido revocado y no se han designado otros beneficiarios con posterioridad o (c) Un beneficiario ha fallecido antes del acaecimiento del siniestro asegurado y no se han designado a otros beneficiarios (...)".

b.2) El derecho propio del beneficiario a la prestación cuando el artículo 17:102 establece: “(6) El asegurador que satisfaga la prestación al beneficiario designado de acuerdo con el párrafo 1 lo liberará de su obligación, salvo que supiese que la persona en cuestión no tenía el derecho a recibirla" y el artículo 17:103 añade: "el tomador del seguro también podrá designar un beneficiario del valor de rescate, si lo hubiese, y podrá modificar o revocar dicha designación. La designación, modificación o revocación deberá realizarse por escrito y enviarse al asegurador. (2) El tomador del seguro se considerará como beneficiario del valor de rescate si (a) No se ha designado un beneficiario del valor de rescate o (b) La designación de un beneficiario del valor de rescate ha sido revocada y no se han designado otros beneficiarios o (c) El beneficiario del valor de rescate fallece y no se han nombrado otros beneficiarios".

c) La cesión o gravamen de la póliza ${ }^{38}$ disponiendo su artículo 17:104: "(1) Cuando un beneficiario haya sido designado de modo irrevocable, la cesión o gravamen del contrato de seguro o el derecho a la prestación del tomador del seguro se dejarán sin efecto salvo que el beneficiario lo consienta por escrito.(2) La cesión o gravamen sobre la prestación por un beneficiario se dejará sin efecto salvo que el tomador del seguro lo consienta por escrito".

d) El deber de información precontractual del solicitante estableciendo el artículo 17:201: “(1) La información a proporcionar por el solicitante de acuerdo con el Artículo 2:101, párrafo 1 deberá incluir aquellas circunstancias que la persona en riesgo conociera o hubiese debido conocer. (2) La sanción por incumplimiento del deber de información precontractual conforme al artículo 2:102, 2:103 y 2:105, pero

\footnotetext{
37 Cfr. art. 88 LCS y ver Sánchez Calero, F. Ley de Contrato de Seguro. Comentarios a la Ley 50/1980, de 8 de octubre, y a sus modificaciones cit., pp. 2322 y ss. y nuestra Guía del Contrato de Seguro cit., pp. $161 \mathrm{y}$ ss.

38 Cfr. art. 99 LCS y ver Sánchez Calero, F. Ley de Contrato de Seguro. Comentarios a la Ley 50/1980, de 8 de octubre, y a sus modificaciones cit., pp. 2572 y ss. y nuestra Guía del Contrato de Seguro cit., pp.176 y ss.
} 
no conforme al Artículo 2:104, sólo será posible durante los cinco años siguientes a la conclusión del contrato".

e) El deber de información precontractual del asegurador cuando el artículo 17:202 dispone: "(1) El asegurador informará al solicitante acerca de su derecho de participación en los beneficios. La recepción de dicha información deberá ser reflejada mediante una declaración explícita contenida en documento distinto al del impreso de solicitud. (2) El documento que el asegurador facilitará de acuerdo con el Artículo 2:201 incluirá la siguiente información: (a) Respecto de asegurador: una expresa referencia a la obligada publicación de sus cuentas anuales y estados financieros. (b) Respecto de los compromisos contractuales asumidos por el asegurado; (i) Una explicación de cada beneficio y cada opción; (ii) Información sobre la proporción de la prima atribuida a cada uno de los beneficios, incluyendo tanto los beneficios principales como los accesorios, cuando corresponda; (iii) Los métodos de cálculo y distribución de los bonus con especial mención de la normativa de supervisión aplicable; (iv) Una indicación de los valores de rescate y desembolsados en la medida en que estén garantizados; (v) Para las pólizas vinculadas a fondos de inversión: una explicación respecto de los fondos de inversión a los que están ligados los beneficios y una indicación sobre la naturaleza de los bienes subyacentes; (vi) Información general sobre el régimen fiscal aplicable al tipo de póliza. 3) Además, deberá proporcionarse información especifica para facilitar la comprensión de los riesgos subyacentes al contrato asumidos por el tomador del seguro.(4) Si el asegurador cita como dato la cantidad de los posibles beneficios y exceden las sumas contractualmente garantizadas, deberá proporcionar al solicitante un modelo de cálculo que contenga los posibles beneficios al momento del vencimiento de la póliza basado en los principios actuariales para el cálculo de la prima con tres distintos tipos de interés. Esto no será de aplicación a aquellos contratos de seguro en los que el asegurador no tenga certeza de su responsabilidad ni a las pólizas vinculadas a fondos de inversión. El asegurador deberá indicar a los tomadores de seguro de forma clara y comprensible que el modelo de cálculo únicamente representa un modelo basado en conjeturas y que el contrato no garantiza los posibles pagos".

f) El periodo de reflexión de un mes tras la recepción de la aceptación o entrega de los documentos mencionados de que dispondrá el tomador (artículo 17:203).

g) El derecho del tomador del seguro de finalizar el contrato cuando el artículo 17:204 establece: "(1) El tomador del contrato tendrá la facultad de finalizar el contrato de seguro sobre la vida que no contenga valores de reducción o rescate, considerando que la finalización no tendrá efecto antes del transcurso del primer año tras la conclusión del contrato. El derecho a finalizar el contrato antes de la finalización del periodo del contrato podrá excluirse cuando solamente una prima haya sido objeto de pago. La finalización deberá realizarse por escrito y surtirá efectos después de dos semanas desde la recepción de la comunicación de finalización por el asegurador".

h) Las modificaciones admisibles durante la vigencia del contrato que exigen el cumplimiento del deber de información postcontractual del asegurador tanto de la información anual mediante una declaración escrita del valor actual de los bonos vinculados a la póliza como de cualquier cambio concerniente a las condiciones de 
la póliza, tanto generales como especiales; de la modificación de las condiciones de la póliza o reforma de los PDECS; así como en los casos en que las cifras relativas a la suma estimada de posibles beneficios sean proporcionadas en cualquier momento durante la vigencia del periodo contractual. En particular, cuando el asegurador, con anterioridad o posterioridad a la conclusión del contrato, haya proporcionado datos acerca del potencial desarrollo de la participación sobre los beneficios, el asegurador informará al tomador del seguro acerca de cualquier diferencia entre los datos inicialmente proporcionados y el desarrollo real (artículo 17:301).

i) La agravación del riesgo, estableciendo el artículo 17:302 que: "En un contrato de seguro sobre la vida, cualquier cláusula que considere la edad o deterioro de la salud como agravación del riesgo dentro del significado del Artículo 4:201 será considerada abusiva conforme al Artículo 2:304". El artículo 17:303 añade. Respecto del "ajuste de la prima y de la prestación” que "(1) En un contrato de seguro sobre la vida que cubra riesgos sobre los cuales el asegurador no tenga certeza de su responsabilidad, el asegurador sólo tendrá la facultad de ajustarlo conforme a los párrafos 2 y 3. (2) Se permitirá un aumento de la prima cuando se produzca un cambio imprevisible y permanente respecto de los riesgos biométricos utilizados como base para el cálculo de la prima, cuando el aumento sea necesario para garantizar la continuación de la capacidad del asegurador de desembolsar los beneficios del contrato de seguro y cuando el aumento haya sido acordado por un técnico independiente o por la autoridad de supervisión. El tomador del seguro tendrá la facultad de compensar el aumento de la prima con la correspondiente reducción de los beneficios. (3) En el caso de una póliza paid-up, el asegurador tendrá la facultad de reducir los beneficios bajo las condiciones establecidas en el párrafo 2. (...)”.

Adviértase que el apartado 2 del art. 11 de la LCS española, para los seguros de personas, elimina el deber de comunicar la variación de las circunstancias de salud del asegurado, "que en ningún caso se considerarán agravación del riesgo». Modificación ésta azonable a la vista de los propios objetos de estos seguros y acorde con la jurisprudencia en la materia ${ }^{39}$.

j) La cobertura del suicidio del asegurado ${ }^{40}$ en los términos establecidos en el artículo 17:502 que dice: “(1) Si, después del transcurso de un año desde la conclusión del contrato, la persona en riesgo se suicida, el asegurador será liberado de su responsabilidad de pago del capital. En ese caso, el asegurador pagará el valor de rescate y cualquier beneficio generado de acuerdo con el Artículo 17:602. (2) El párrafo 1 no será de aplicación si (a) La persona en riesgo, en el momento de suicidarse, actúa en un estado mental que le impide tomar libremente la decisión; (b) Queda probada cualquier duda razonable acerca de la intención de suicidio de la persona en riesgo en el momento de concluir el contrato".

k) Los valores garantizados de reducción y rescate disponiendo:

\footnotetext{
39 Ver nuestra Guía del Contrato de Seguro cit., pp. 75 y ss.

40 Cfr. art. 93 LCS y ver Sánchez Calero, F. Ley de Contrato de Seguro. Comentarios a la Ley 50/1980, de 8 de octubre, y a sus modificaciones cit., pp. 2460 y ss. y nuestra Guía del Contrato de Seguro cit., pp. 175 y ss.
} 
k.1) Su artículo 17:601 respecto a la reducción ${ }^{41}$ del contrato: "(1) El artículo 5:103 no será de aplicación a los contratos de seguro sobre la vida que tengan asociados valores de reducción o de rescate. Dichos contratos se convertirán en pólizas paid-up salvo que el tomador del seguro requiera el pago del valor de rescate dentro de las cuatro semanas siguientes a la recepción de la información referida en el párrafo 2. (2) El asegurador informará al tomador del contrato de los valores de reducción y rescate dentro de las cuatro semanas desde el vencimiento del periodo contemplado en el Artículo 5:101(b) o el Artículo 5:102 párrafo 1(b) y solicitará al tomador del seguro la elección entre la reducción y el pago del valor de rescate".

k.2) Su artículo 17:602 sobre el rescate ${ }^{42}$ del contrato: “(1) El tomador del seguro podrá solicitar por escrito en cualquier momento al asegurador el valor de rescate asociado a la póliza, de forma total o parcial, siempre y cuando no surta efectos con anterioridad al transcurso de un año desde la conclusión del contrato. El contrato se ajustará o finalizará de acuerdo con ello. (2) Sin perjuicio de lo establecido en el Artículo 17:601, si un contrato de seguro sobre la vida que tiene asociado un valor de rescate es finalizado, rescindido o anulado por el asegurador, será obligatorio el abono del valor de rescate, incluso en el caso del Artículo 2:104. (3) El asegurador informará al tomador del seguro a petición de éste y, en todo caso, anualmente sobre la cuantía actual del valor de rescate y el alcance de la cuantía garantizada. (4) La parte de beneficio al que el tomador del seguro tiene derecho deberá abonarse además del valor de rescate, salvo que esta parte ya se haya tenido en consideración para el cálculo del valor de rescate. (5) Las cantidades debidas de acuerdo con el presente Artículo se abonarán no más tarde del transcurso de dos meses tras la recepción por parte del asegurador de la solicitud del tomador del seguro".

\footnotetext{
${ }^{41}$ Cfr. art. 95 LCS y ver SÁnchez Calero, F. Ley de Contrato de Seguro. Comentarios a la Ley 50/1980, de 8 de octubre, y a sus modificaciones cit., pp. 2499 y ss. y nuestra Guía del Contrato de Seguro cit., pp. 182 y ss.

42 Cfr. art. 96 LCS y ver SánChez Calero, F. Ley de Contrato de Seguro. Comentarios a la Ley 50/1980, de 8 de octubre, y a sus modificaciones cit., pp. 2519 y ss. y nuestra Guía del Contrato de Seguro cit., pp. 185 y ss.
} 
